\title{
Effect of Lactobacillus acidophilus NS1 on plasma cholesterol levels in diet-induced obese mice
}

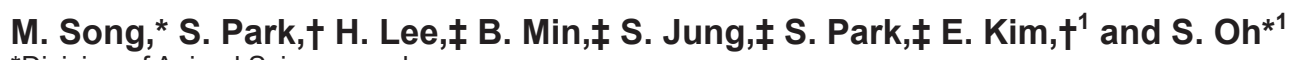 \\ *Division of Animal Science, and \\ †Department of Biological Sciences, Chonnam National University, 77 Yongbong-ro, Buk-gu, Gwangju, 500-757, Republic of Korea \\ †Research \& Business Development Center, Nong Shim Co. Ltd., 112 Yeouidaebang-ro, Seoul, 156-709, Republic of Korea
}

\section{ABSTRACT}

We investigated the probiotic properties of Lactobacillus acidophilus NS1, such as acid resistance, bile tolerance, adherence to HT-29 cells, and cholesterol assimilation activity. In an animal study, 7 -wk-old male C57BL/6 mice were fed a normal diet, a high-fat diet (HFD), or an HFD with L. acidophilus NS1 (ca. 1.0 $\times 10^{8} \mathrm{cfu} / \mathrm{mL}$ ) for $10 \mathrm{wk}$. Total cholesterol and lowdensity lipoprotein (LDL) cholesterol levels were significantly lower in mice fed an HFD with $L$. acidophilus NS1 than in those fed an HFD only, whereas high-density lipoprotein cholesterol levels were similar between these 2 groups. To understand the mechanism of the cholesterol-lowering effect of $L$. acidophilus NS1 on the HFD-mediated increase in plasma cholesterol levels, we determined mRNA levels of genes involved in cholesterol homeostasis in the liver. Expression of sterol regulatory element-binding protein 2 (Srebp2) and LDL receptor $(L d l r)$ in the liver was dramatically reduced in mice fed a HFD compared with those fed a normal diet. When L. acidophilus NS1 was administered orally to HFD-fed mice, an HFD-induced suppression of Srebp2 and Ldlr expression in the liver was abolished. These results suggest that the oral administration of L. acidophilus NS1 to mice fed an HFD increased the expression of Srebp2 and $L d l r$ in the liver, which was inhibited by high fat intake, thus leading to a decrease in plasma cholesterol levels. Lactobacillus acidophilus NS1 could be a useful probiotic microorganism for cholesterol-lowering dairy products and the improvement of hyperlipidemia and hepatic lipid metabolism.

Key words: cholesterol, Lactobacillus acidophilus, obesity, probiotic

Received July 9, 2014

Accepted September 21, 2014.

${ }^{1}$ Corresponding authors: ekim@chonnam.ac.kr and soh@chonnam. ac.kr

\section{INTRODUCTION}

Cardiovascular diseases (CVD), such as atherosclerosis and coronary heart disease, are the leading cause of death in the United States (Anderson, 2002). Hypercholesterolemia due to elevated serum low-density lipoprotein $(\mathbf{L D L})$ cholesterol levels is a major risk factor for CVD. Meta-analysis showed that a $1 \%$ decrease in serum cholesterol could reduce the risk of CVD by 2 to 3\% (Manson et al., 1992). The liver is a critical organ for clearance of LDL cholesterol (LDL-C) from the circulating blood, and LDL receptor $(L D L R)$-mediated endocytosis in liver accounts for removing 70 to $80 \%$ of serum LDL-C (Brown and Goldstein, 1986; Spady, 1992). Thus, a complementary relationship between hepatic $L D L R$ expression and serum LDL-C level has been well established, indicating that $L D L R$ is a promising target to prevent the development and progression of CVD.

Lactobacilli play a major role in the dairy industry and are used in the production of cheese and yogurts. Lactobacilli are considered to have antimutagenic and anticarcinogenic activities, enhance immune responses, and inhibit pathogens (du Toit et al., 1998; Nguyen et al., 2007). In addition, recent studies have reported that lactobacilli have hypocholesterolemic effects, implicating a beneficial role for lactobacilli in coronary artery diseases (Ooi and Liong, 2010)

Yogurt containing Lactobacillus strains induce resistance to diet-induced BW gain and increased plasma cholesterol and triglyceride levels. Although several potential mechanisms have been proposed, how lactobacilli reduce serum cholesterol levels has not been well established. One of the proposed mechanisms is the assimilation of cholesterol by Lactobacillus acidophilus. Some lactobacilli, including Lactobacillus spp., Bifidobacterium longum, Clostridium perfringens, and Bacteroides fragilis ssp. fragilis, produce bile salt hydrolase, which facilitates the deconjugation of bile acid salts. Bile salt hydrolase (EC 3.5.1.24) catalyzes the hydrolysis of glycine- or taurine-conjugated bile salts into AA residues and free bile salts. The deconjugation of bile acid by Lactobacillus bile salt hydrolase interferes 
Table 1. Selected strains of Lactobacillus used in this study

\begin{tabular}{llc}
\hline Strain & Origin & $\begin{array}{c}\text { Incubation } \\
\text { temperature }\left({ }^{\circ} \mathrm{C}\right)\end{array}$ \\
\hline Lactobacillus acidophilus KU41 & Infant feces & 37 \\
Lactobacillus acidophilus NS1 & Infant feces & 37 \\
Lactobacillus acidophilus M23 & Infant feces & 37 \\
Lactobacillus brevis CH7 & Kimchi & 37 \\
Lactobacillus casei MYB3 & Kimchi & 37 \\
Lactobacillus fermentum NS2 & Kimchi & 37 \\
Lactobacillus plantarum M13 & Kimchi & 37 \\
Lactobacillus plantarum NS3 & Kimchi & 37 \\
Lactobacillus sakei CH8 & Fermented olive & 37 \\
Lactobacillus sakei MYA9 & Fermented olive & \\
\hline
\end{tabular}

with the enterohepatic circulation of bile salts. This interference may lead to a decrease in serum cholesterol concentrations because cholesterol is the precursor for the de novo synthesis of new bile acids (Pereira and Gibson, 2002; Liong and Shah, 2005). The production of short-chain FA by probiotics upon fermentation may be another mechanism that contributed to the cholesterol decrease. Short-chain FA can inhibit hepatic cholesterol synthesis.

Some reports suggest that a single probiotic or a mixture of probiotics could regulate cholesterol synthesis in the liver (Park et al., 2008b; Ooi and Liong, 2010). This inhibition of cholesterol synthesis was caused by a decrease in the activity of hydroxymethyl glutarate (HMG) CoA reductase, the rate-limiting enzyme of the mevalonate pathway. In other reports, some strains of lactic acid bacteria (LAB) lowered cholesterol in circulation through induction of hepatic $L D L R$ expression, which removes LDL-C from circulation, leading to catabolism of cholesterol in the liver (Park et al., 2008b). Reductions of total plasma and LDL-C are major strategies to decrease the risk of cardiovascular diseases (Liong and Shah, 2005).

The aim of our study was to select Lactobacillus strains that have potential probiotic properties, such as acid resistance, bile tolerance, adherence to HT-29 cells, and cholesterol assimilation. We also evaluated whether selected probiotics effectively reduce plasma cholesterol levels in mice fed a high-fat diet.

\section{MATERIALS AND METHODS}

\section{Isolation of Lactobacillus Species}

The selected Lactobacillus strains were shown in Table 1. Ten strains of Lactobacillus were inoculated on plates of de Man, Rogosa, and Sharpe (MRS) agar (Difco, Detroit, MI) and then incubated for $48 \mathrm{~h}$ at $37^{\circ} \mathrm{C}$. Colonies with typical characteristics were randomly selected. The selected colonies were inoculated onto MRS agar plates with $0.004 \%$ bromocresol purple
(Junsei Chemical Co. Ltd., Tokyo, Japan) and yellow colonies were reisolated. The morphological and phenotypic characteristics of the colonies and cells of strains grown on the MRS agar plates were recorded. This characterization of the strains was based on Bergey's Manual of Determinative Bacteriology (Kandler and Weiss, 1986). The Gram stain and catalase and oxidase tests were performed to ensure that no contamination with gram-negative microorganisms occurred. Cultures were maintained in $10 \%$ skim milk with $1 \%$ glucose and $0.3 \%$ yeast extract and stored at $-80^{\circ} \mathrm{C}$.

\section{S Ribosomal DNA Extraction}

Probiotic strains were inoculated for $18 \mathrm{~h}$ at $37^{\circ} \mathrm{C}$ in MRS broth and subcultured under the same conditions. Two milliliters of culture medium were centrifuged $\left(3,000 \times g, 10 \mathrm{~min}, 4^{\circ} \mathrm{C}\right)$. The pellets were washed 3 times with $0.85 \% \mathrm{NaCl}$ (Sigma, St. Louis, Mo). After washing, $0.5 \mathrm{~mL}$ of lysozyme (Sigma; $10 \mathrm{mg} / \mathrm{mL}$ ) was added and left at $37^{\circ} \mathrm{C}$ for $1 \mathrm{~h}$. After adding $20 \mu \mathrm{L}$ of proteinase K (Sigma; $10 \mathrm{mg} / \mathrm{mL}$ ) and $25 \mu \mathrm{L}$ of $10 \%$ SDS (Sigma), the suspensions were incubated in a water bath at $60^{\circ} \mathrm{C}$ for $30 \mathrm{~min}$. Next, $1 \mu \mathrm{L}$ of RNase was added and the samples were incubated at $37^{\circ} \mathrm{C}$ for 1 h. Equal volumes of phenol:chloroform:isoamyl alcohol (25:24:1) were added, mixed well, and the mixture was centrifuged for $5 \mathrm{~min}$ at $14,000 \times g$ and $4^{\circ} \mathrm{C}$. After adding a half volume of $3 \mathrm{M}$ sodium acetate ( $\mathrm{pH} 4.8$ ) and 2 volumes of $100 \%$ ethyl alcohol to the supernatant in each tube, the samples were kept for $1 \mathrm{~h}$ at $-20^{\circ} \mathrm{C}$. The samples were centrifuged for 5 min at $14,000 \times$ $g$ and $4^{\circ} \mathrm{C}$. The DNA pellet was washed with $1 \mathrm{~mL}$ of $70 \%$ alcohol, centrifuged under the same conditions, and then dried.

\section{Identification of Lactobacillus Strains}

The amplification reactions of the DNA sample were performed in a $0.2-\mathrm{mL}$ PCR single tube with hinged 
flat cap in an eppendorf. The $16 \mathrm{~S}$ ribosomal DNA (rDNA) was amplified using PCR premix (Bioneer, Dejeon, South Korea; Cat No. K-2012). The PCR premix was mixed with $1 \mu \mathrm{L}$ of forward primer, $1 \mu \mathrm{L}$ of reverse primer, $1 \mu \mathrm{L}$ of DNA, and $17 \mu \mathrm{L}$ of distilled water. The primers used in this study were: $27 \mathrm{f}, 5^{\prime}$ AGA GTT TGA TCM TGG CTC AG-3' and 1492r, 5'GGT TAC CTT GTT ACG ACT T-3'. The PCR amplification reaction was $94^{\circ} \mathrm{C}$ for $5 \mathrm{~min}$, followed by 30 cycles of $94^{\circ} \mathrm{C}$ for $60 \mathrm{~s}, 62^{\circ} \mathrm{C}$ for $40 \mathrm{~s}$, and $72^{\circ} \mathrm{C}$ for $40 \mathrm{~s}$, and a final elongation step at $72^{\circ} \mathrm{C}$ for $7 \mathrm{~min}$. The PCR product was analyzed by electrophoresis in a $0.8 \%$ agarose gel (Promega, Madison, WI) at $100 \mathrm{~V}$ for $20 \mathrm{~min}$, and gels were then visualized using UV transillumination (Kermanshahi and Peymanfar, 2012). Sequence analysis was performed by Solgent (Daejeon, South Korea). The $16 \mathrm{~S}$ rDNA sequencing analysis was performed using the basic local alignment search tool (BLAST).

\section{Acid and Bile Acid Tolerance}

The method used for testing bile acid tolerance was similar to that described by Hyronimus et al. (2000). The MRS broth was inoculated and incubated at $37^{\circ} \mathrm{C}$ for $18 \mathrm{~h}$. Test cultures were supplemented with $0.3 \%$ oxgall. All samples were incubated for $24 \mathrm{~h}$ at $37^{\circ} \mathrm{C}$. Resistant strains in the bile acid tolerance were used for acid tolerance testing.

Cultures were grown in MRS broth at $37^{\circ} \mathrm{C}$ for $18 \mathrm{~h}$ and subcultured in $10 \mathrm{~mL}$ of fresh MRS broth adjusted to $\mathrm{pH} 2.5$ with 1,000 units/mL of pepsin (Sigma). The initial bacterial concentration was $1.0 \times 10^{8} \mathrm{cfu} / \mathrm{mL}$, and samples were incubated for 0 and $2 \mathrm{~h}$ at $37^{\circ} \mathrm{C}$. Cultures $\left(1.0 \times 10^{8} \mathrm{cfu} / \mathrm{mL}\right)$ were serially diluted 10 -fold in $0.05 M$ sodium phosphate buffer to neutralize the medium acidity. Viable bacterial colonies were determined by dilution plate counting on MRS agar after 24 to $48 \mathrm{~h}$ of incubation. Each experiment was conducted in triplicate.

\section{Cholesterol Assimilation}

The cholesterol assimilation assay was performed according to the methods described by Buck and Gilliland (1994). The strains were inoculated MRS broth (polyoxyethanyl cholesteryl sebacate $0.045 \%$ and cysteine $0.05 \%$ ) for $24 \mathrm{~h}$ under anaerobic conditions and then centrifuged $\left(12,000 \times g, 10 \mathrm{~min}, 4^{\circ} \mathrm{C}\right)$. A total of $0.5 \mathrm{~mL}$ of supernatant fluid was collected and added to and then reacted in a water bath at $60^{\circ} \mathrm{C}$ for $5 \mathrm{~min}$. After cooling, the cells were added to $5 \mathrm{~mL}$ of hexane and mixed. A 3-mL aliquot of distilled water was added, mixed, and clean tubes were allowed to stand for 15 min at room temperature to allow for phase separation. A 2.5-mL aliquot of hexane layer fluid was transferred to new tube, and the hexane was evaporated under nitrogen gas. After the remaining solution was treated with $4 \mathrm{~mL}$ of $o$-phthalaldehyde reagent $(0.5 \mathrm{mg}$ of $o$ phthalaldehyde/ $1 \mathrm{~mL}$ of glacial acetic acid), $2 \mathrm{~mL}$ of sulfuric acid was added and reacted for $10 \mathrm{~min}$. The results were monitored by measuring absorbance with a microplate reader (Synergy HT, Bio-Tek, Winooski, VT) at $550 \mathrm{~nm}$. Each experiment was conducted in triplicate.

\section{Adhesion Assay}

The observation of attachment assays was performed using the method of Kim et al. (2008) with slight modifications. The HT-29 or HT-29 DM2 monolayers were prepared as described previously. The monolayers of HT-29 cells (KCTC, Daejeon, South Korea) were washed 5 times in PBS and overlaid with $0.5 \mathrm{~mL}$ of RPMI 1640 medium (Gibco BRL, Grand Island, NY). A total of $1.0 \times 10^{9} \mathrm{cfu} / \mathrm{mL}$ of strains in antibiotic-free medium were mixed, inoculated to each well, and then incubated for 0 and $24 \mathrm{~h}$ at $37^{\circ} \mathrm{C}$. The monolayers were then washed 3 times by centrifugation at approximately $200 \times g$ in PBS to remove any unattached bacteria. The adherent cells were released from well plates using $0.2 \%$ trypsin-EDTA and incubated for $5 \mathrm{~min}$ at $37^{\circ} \mathrm{C}$ in $5 \% \mathrm{CO}_{2} / 95 \%$ air atmosphere. The number of viable cells was determined using the spread plate method on MRS agar with incubation at $37^{\circ} \mathrm{C}$ for $48 \mathrm{~h}$. Each experiment was conducted in triplicate.

\section{Animals}

The C57BL/ 6 male mice ( 7 wk old and $19 \pm 2 \mathrm{~g}$ of weight) were purchased from Damul Science (Daejeon, Korea). All mice used in the experiments were housed in groups of 4 per cage with $12 \mathrm{~h}$ of light and $12 \mathrm{~h}$ of dark cycles in an ambient temperature of $25 \pm 1{ }^{\circ} \mathrm{C}$. Animal tests were conducted in accordance with the guidelines of the Institutional Animal Care and Use Committee at Chonnam National University (CNU IACUC-YB-2012-40).

\section{Experimental Design}

Mice were fed a normal diet of standard rodent chow (ND; $16 \%$ of calories from fat) or a high-fat diet (HFD; $45 \%$ of calories from fat). The composition of experimental diets was shown in Table 2 . The selected Lactobacillus acidophilus NS1 $\left(\sim 1.0 \times 10^{8} \mathrm{cfu} / \mathrm{mL}\right)$ was orally administered daily for $10 \mathrm{wk}$ to mice housed in cages. During the experimental period, BW was mea- 
Table 2. Composition of the experimental diets

\begin{tabular}{|c|c|c|}
\hline Item & Normal diet & High-fat diet \\
\hline \multicolumn{3}{|l|}{ Ingredient (g) } \\
\hline Casein (from milk) & 200 & 200 \\
\hline Corn starch & 397 & 155 \\
\hline Sucrose & 100 & 50 \\
\hline Dextrose & 132 & 132 \\
\hline Cellulose & 50 & 50 \\
\hline Soybean oil & 70 & 2 \\
\hline SFA & 10.96 & 3.91 \\
\hline MUFA & 15.95 & 5.7 \\
\hline PUFA & 40.42 & 14.44 \\
\hline Lard & 0 & 175 \\
\hline SFA & & 70 \\
\hline MUFA & & 78.93 \\
\hline PUFA & & 19.6 \\
\hline Cholesterol (mg) & & 126 \\
\hline Mineral mixture & 35 & 35 \\
\hline Vitamin mixture & 10 & 10 \\
\hline $\mathrm{TBHQ}^{1}$ & 0.014 & 0.014 \\
\hline L-Cys & 3 & 3 \\
\hline Choline bitartrate & 2.5 & 2.5 \\
\hline Total amount (g) & 1,000 & 837.6 \\
\hline Gross energy content (kcal/kg) & 4,000 & 4,776 \\
\hline Calories from protein $(\%)$ & 20 & 20 \\
\hline Calories from fat $(\%)$ & 16 & 45 \\
\hline
\end{tabular}

${ }^{1} \mathrm{TBHQ}=$ tert-butylhydroquinone.

sured once a week. Mice were allowed ad libitum access to preweighed diets in each cage. The remaining diet feed was weighed every day for 3 consecutive days at the last week of feeding period to measure food intake.

\section{Cholesterol and Triglyceride Levels}

Total cholesterol (TC), LDL-C, high-density lipoprotein (HDL) cholesterol (HDL-C), and triglyceride (TG) levels were measured in plasma and livers from each group of mice using a Cholesterol/Cholesteryl Ester Quantitation kit (Biovision, Mountain View, CA) and a Triglyceride Assay kit (Biovision) according to the manufacturer's recommended protocols.

\section{Semiquantitative Reverse Transcription PCR}

To determine the expression of genes involved in cholesterol homeostasis in the liver, total RNA was isolated using RiboEx solution (GeneAll Biotechnology, Seoul, Korea) according to the manufacturer's protocol. The cDNA was synthesized using Moloney murine leukemia virus reverse transcriptase and oligo-dT primers (Promega). The mRNA levels of genes were determined by semiquantitative reverse transcription-PCR as described previously (Park et al., 2008a). The relative abundance of target mRNA was quantified relative to the internal control, 36B4, a ribosomal protein. Primer sequences are shown in Table 3.

\section{Statistical Analysis}

All values are expressed as mean $\pm \mathrm{SD}$. The data were analyzed by $t$-test and one-way ANOVA using SPSS ver. 18.0 (SPSS Inc., Chicago, IL). The differences between groups were assessed using Duncan's multiple range test. Statistical significance was considered at $\alpha<0.05$.

\section{RESULTS AND DISCUSSION}

\section{Acid and Bile Acid Tolerance}

The acid and bile acid tolerance of selected strains of Lactobacillus were shown in Table 4. All strains showed tolerance to $\mathrm{pH} 2.5$ for $2 \mathrm{~h}$ despite variations in the degree of viability. Lactobacillus acidophilus KU41, L. acidophilus NS1, Lactobacillus brevis CH7, Lactobacillus fermentum NS2, Lactobacillus plantarum M13, and Lactobacillus sakei CH8 were the most acidtolerant strains, with more than $10^{6} \mathrm{cfu} / \mathrm{mL}$ of bacteria present after incubation at $\mathrm{pH} 2.5$ for $2 \mathrm{~h}$, whereas L. acidophilus M23 was the most acid-sensitive strain, with only $10^{4}$ total $\mathrm{cfu} / \mathrm{mL}$ of bacteria after the 2 -h incubation. Because some strains have numerous acidshock proteins that promote survival, they are capable of surviving exposure to extreme acidic environments (Merrell and Camilli, 2002). In general, strains of $L$. acidophilus showed greater acid tolerance. The word probiotic means to live and describes microorganisms 
Table 3. Primer sequences used for real-time PCR in this study

\begin{tabular}{lll}
\hline Gene & Forward primers $\left(5^{\prime}-3^{\prime}\right)$ & Reverse primers $\left(5^{\prime}-3^{\prime}\right)$ \\
\hline Liver X receptor & CTCTTCTTGCCGCTTCAGTT & AGGAGTGTCGACTTCGCAAA \\
Farnesoid X receptor & CCAACCTGGGCTTCTACCC & CACACAGCTCATCCCCTTT \\
Sterol regulatory element-binding protein 2 & AGCAGCAGGTGCAGACGGTA & CATCTGTCTTCAGCGTGGTC \\
Hydroxymethyl glutarate-CoA reductase & AAGGGTACGGAGAAAGCACT & AATGACGCTTCACAAACCA \\
Low-density lipoprotein receptor & AGCAGTGAGTGTATCCATCG & AATGCAGGAGCCATCTGCAC \\
Cholesterol 7 -hydroxylase & ATTCCATACCTGGGCTGTGC & ATGTTTTCAGTGGTATTTCC \\
$36 B 4$ & AGATGCAGCAGATCCGCAT & ATATGAGGCAGCAGTTTCTCC \\
\hline
\end{tabular}

(in most cases, bacteria) that survive passage through the gastrointestinal tract and have beneficial effects on the host (Wang et al., 2012).

Acid-tolerant strains have an advantage in surviving the low-pH conditions in the stomach $(\mathrm{pH} 2.0$ in extreme cases) where hydrochloric and gastric acids are secreted (du Toit et al., 1998). In determining the effects of oxgall on the growth of selected strains, $L$. acidophilus NS1, L. acidophilus M23, L. casei MYB3, and L. sakei MYA9 were found to have full tolerance to $0.3 \%$ bile. These results indicate that bile at $0.3 \%$ does not affect the viability of these 4 strains and that all isolates grew in the presence of $0.3 \%$ bile. Generally, the physiological concentrations of human bile range from 0.3 to $0.5 \%$ (Dunne et al., 2001). Therefore, resistance to bile acid is an important characteristic that enables Lactobacillus to survive, grow, and exert action in the small intestine (du Toit et al., 1998; Hyronimus et al., 2000). These results suggest that bacteria that are resistant to stomach and intestinal conditions are important and that L. acidophilus NS1 demonstrates acid and bile acid tolerance.

\section{Cholesterol Assimilation and Adhesion Assay}

Table 4 shows the results from the cholesterol assimilation activity and adhesion assays of selected strains of Lactobacillus. Lactobacillus acidophilus KU41, L. acidophilus NS1, L. acidophilus M23, L. fermentum NS2,
L. plantarum M13, and L. plantarum NS3 were found to reduce cholesterol levels by $>50 \%$ in the in vitro test. Lactobacillus sakei $\mathrm{CH} 8$ was found to decrease cholesterol by $30 \%$, and L. brevis $\mathrm{CH} 7$ and L. casei MYB3 decreased cholesterol less than $30 \%$.

Adhesion and colonization at the intestinal surface may be important prerequisites for probiotic strains to have a beneficial effect in the large intestine (Lim, 2014). The selected strains of Lactobacillus were similarly studied for adhesion to HT-29 cells. In our study, L. acidophilus NS1 was evaluated with regard to its ability to inhibit attachment to HT-29 cells. Kim et al. (2008) reported that L. acidophilus ATCC 43121 demonstrated this ability in an adhesion assay. The viable cells of L. acidophilus NS1 decreased from the initial cell counts after $2 \mathrm{~h}$. However, compared with results of Kim et al. (2008), adhesion of L. acidophilus NS1 showed high cell viability.

\section{Lactobacillus acidophilus NS1 Inhibits HFD-Induced BW Gain}

To evaluate the suppressive effect of probiotic $L$. acidophilus NS1 on diet-induced hypercholesterolemia, we fed an HFD with or without oral administration of $L$. acidophilus NS1 to 7 -wk-old mice for $10 \mathrm{wk}$. In addition, we used ND-fed mice as a control group to determine changes in lipid parameters caused by HFD feed.

Table 4. The probiotic properties of selected strains of Lactobacillus

\begin{tabular}{|c|c|c|c|c|c|c|c|}
\hline \multirow[b]{2}{*}{ Strain } & \multicolumn{2}{|c|}{ Pepsin at $\mathrm{pH} 2.5(\mathrm{cfu} / \mathrm{mL})$} & \multicolumn{2}{|c|}{$0.3 \%$ Oxgall $(\mathrm{cfu} / \mathrm{mL})$} & \multirow{2}{*}{$\begin{array}{c}\text { Cholesterol } \\
\text { assimilation (\%) }\end{array}$} & \multicolumn{2}{|c|}{ Adhesion assay (cfu/mL) } \\
\hline & $0 \mathrm{~h}$ & $2 \mathrm{~h}$ & $0 \mathrm{~h}$ & $24 \mathrm{~h}$ & & $0 \mathrm{~h}$ & $24 \mathrm{~h}$ \\
\hline Lactobacillus acidophilus KU41 & $2.20 \times 10^{8}$ & $1.70 \times 10^{7}$ & $2.28 \times 10^{6}$ & $3.46 \times 10^{5}$ & 53.20 & $3.13 \times 10^{10}$ & $3.46 \times 10^{5}$ \\
\hline Lactobacillus acidophilus NS1 & $2.30 \times 10^{8}$ & $1.76 \times 10^{6}$ & $2.18 \times 10^{6}$ & $4.45 \times 10^{6}$ & 55 & $1.39 \times 10^{10}$ & $4.45 \times 10^{6}$ \\
\hline Lactobacillus acidophilus M23 & $1.60 \times 10^{8}$ & $1.27 \times 10^{4}$ & $1.07 \times 10^{6}$ & $3.87 \times 10^{6}$ & 52.25 & $1.65 \times 10^{10}$ & $3.87 \times 10^{6}$ \\
\hline Lactobacillus brevis $\mathrm{CH} 7$ & $2.00 \times 10^{8}$ & $5.00 \times 10^{7}$ & $6.32 \times 10^{6}$ & $1.08 \times 10^{7}$ & 29 & $7.30 \times 10^{9}$ & $1.08 \times 10^{7}$ \\
\hline Lactobacillus casei MYB3 & $1.24 \times 10^{7}$ & $4.50 \times 10^{5}$ & $7.84 \times 10^{6}$ & $6.65 \times 10^{8}$ & 20.53 & $1.04 \times 10^{1}$ & $6.65 \times 10^{8}$ \\
\hline Lactobacillus fermentum NS2 & $8.15 \times 10^{7}$ & $1.29 \times 10^{6}$ & $1.36 \times 10^{6}$ & $6.90 \times 10^{3}$ & 57.07 & $8.15 \times 10^{7}$ & $6.90 \times 10^{3}$ \\
\hline Lactobacillus plantarum M13 & $3.53 \times 10^{8}$ & $2.00 \times 10^{7}$ & $7.98 \times 10^{5}$ & $7.48 \times 10^{2}$ & 54.81 & $1.09 \times 10^{10}$ & $7.48 \times 10^{2}$ \\
\hline Lactobacillus plantarum NS3 & $3.90 \times 10^{7}$ & $7.70 \times 10^{5}$ & $7.83 \times 10^{5}$ & $3.09 \times 10^{3}$ & 71.16 & $1.64 \times 10^{10}$ & $3.09 \times 10^{3}$ \\
\hline Lactobacillus sakei $\mathrm{CH} 8$ & $2.00 \times 10^{7}$ & $1.90 \times 10^{8}$ & $7.83 \times 10^{5}$ & $1.63 \times 10^{7}$ & 30.00 & $6.34 \times 10^{9}$ & $1.63 \times 10^{7}$ \\
\hline Lactobacillus sakei MYA9 & $1.63 \times 10^{7}$ & $1.50 \times 10^{5}$ & $6.94 \times 10^{6}$ & $4.20 \times 10^{8}$ & 41.24 & $3.01 \times 10^{10}$ & $4.20 \times 10^{8}$ \\
\hline
\end{tabular}


By the end of the feeding period, the average BW of HFD-fed mice increased approximately 18\% compared with mice fed with ND-fed mice. In contrast, when mice were fed a HFD with $L$. acidophilus NS1 administration (HFD-NS1), BW increase due to HFD feeding was inhibited by $81 \%$ (Figure 1A). Because LAB administration may reduce food intake, leading to a resistance to an HFD-induced increase of BW, we monitored total food intake and observed no significant differences in total food intake among all the experimental groups (Figure 1B). Consistent with our results, other studies have also shown that some strains of Lactobacillus have antiobesity effects when administered with an HFD (Lee et al., 2006; Tanida et al., 2008). Together, our results suggest that an HFD-induced increase in BW in mice could be significantly prevented by administration of L. acidophilus NS1.

\section{Plasma Cholesterol and TG Levels}

Several studies have shown that Western diets increase cholesterol levels in circulation and that chronic administration of some LAB has an inhibitory effect on diet-induced plasma lipid levels. Because HFD-NS1 mice showed resistance to HFD-induced obesity, we investigated whether L. acidophilus NS1 has a beneficial effect on HFD-induced hyperlipidemia. As shown in Figure 2A, mice fed an HFD for 10 wk showed $20 \%$ higher plasma TC levels than ND mice. In contrast, when $L$. acidophilus NS1 supplemented an HFD, the effect of an HFD in increasing TC levels was significantly inhibited. Next, we measured plasma LDL-C and HDL$\mathrm{C}$ levels to determine which cholesterols contribute to a reduction in TC. Plasma LDL-C levels in HFD-fed mice were approximately $32 \%$ higher than those of ND mice. In addition, plasma LDL-C levels in mice fed an HFD was reduced approximately $18 \%$ by L. acidophilus NS1 administration. However, plasma HDL-C levels were similar between the HFD only and HFD-NS1 feeding groups (Figure 2A). Accordingly, several studies reported that LAB reduced diet-induced plasma LDL$\mathrm{C}$ with no change in HDL-C, although L. plantarum 9-41-A was shown to increase plasma HDL-C levels in rats (Xie et al., 2011). Although the conflicting effects of LAB on plasma HDL-C are not easy to explain, they could be due to differences in the properties of different bacterial strains. Together, our data suggest that $L$. acidophilus NS1 inhibition of HFD-induced increases in TC may be accomplished by reduction of LDL-C. Because HFD raises TG levels together with cholesterol levels in circulation, we also determined plasma TG levels to test whether L. acidophilus NS1 can also inhibit diet-induced plasma TG levels. As expected, a HFD increased plasma TG levels approximately $51 \%$
(A)

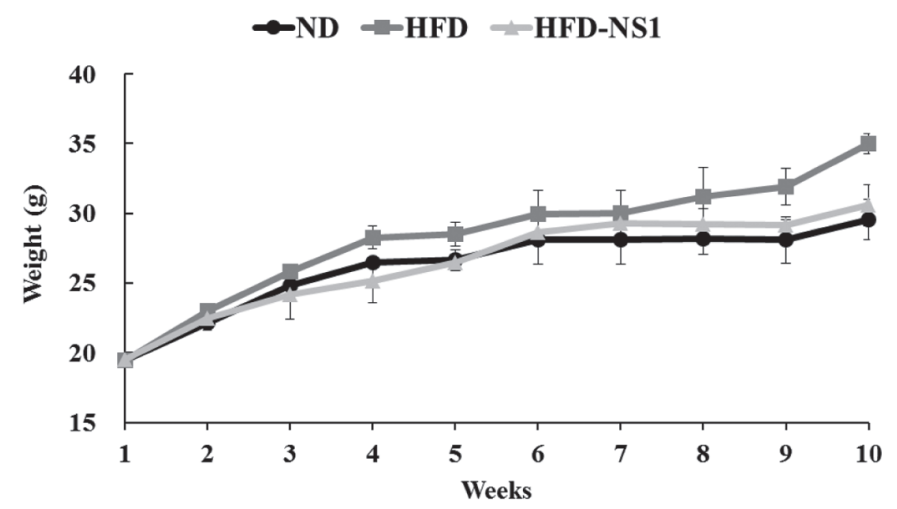

(B)

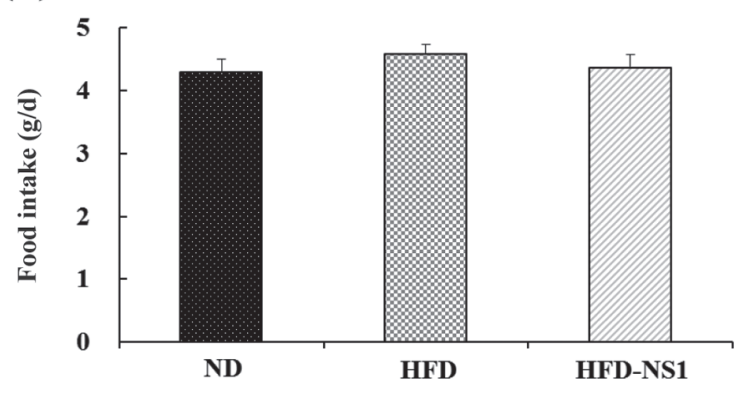

Figure 1. Lactobacillus acidophilus NS1 suppresses BW gain in high-fat diet (HFD)-fed mice without reduction of food intake. (A) Seven-week-old male mice were fed a normal diet (ND), HFD, or HFD with $L$. acidophilus NS1 (HFD-NS1) for $10 \mathrm{wk}$ and the average BW gains of ND $(\mathrm{n}=6)$, HFD $(\mathrm{n}=5)$, and HFD-NS1 mice $(\mathrm{n}=6)$ were calculated and plotted. (B) Food intakes of mice fed ND, HFD, or HFD-NS1 were measured every day for $3 \mathrm{~d}$. The error bars indicate the standard deviations.

after a 10 -wk feeding period compared with ND feeding (Figure 2B). However, when HFD-NS1 was fed for the whole feeding period, plasma TG levels were $54 \%$ lower than those of HFD-fed mice (Figure 2B), suggesting that L. acidophilus NS1 has a suppressive effect on dietinduced hyperlipidemia. However, we do not know the effect of $L$. acidophilus NS1 on lipid profiles in mice fed a ND. Prolonged HFD feeding worsens the lipid profile in part by alteration of metabolic gene expression, which is closely associated with HFD-induced perturbation of the intestinal microbial flora (Daniel et al., 2014). Probiotics have been shown to improve plasma lipid profiles through restoration of gut microbiota composition, which is perturbed by a HFD, followed by normalization of altered metabolic gene expression (Yoo et al., 2013). Because healthy gut microbiota is closely associated with a lean and healthy condition, probiotics, including L. acidophilus NS1, may not show a dramatic beneficial effect in lowering plasma lipid levels in lean mice that are fed an ND and have a normal lipid profile. Accordingly, Lactobacillus plantarum 
Table 5. Alteration of atherogenic indices in high-fat diet (HFD)-fed mice that received Lactobacillus acidophilus $\mathrm{NS}^{1}$

\begin{tabular}{lccc}
\hline Group & HDL-C/TC & HDL-C/LDL-C & TG/HDL-C \\
\hline ND & 0.84 & 2.62 & 0.32 \\
HFD & 0.69 & 1.82 & 0.64 \\
HFD-NS1 & 0.78 & 2.12 & 0.31
\end{tabular}

${ }^{1} \mathrm{ND}=$ normal diet; HFD-NS1 = HFD plus Lactobacillus acidophilus NS1; LDL-C = low-density lipoprotein cholesterol; HDL-C $=$ highdensity lipoprotein cholesterol; $\mathrm{TG}=$ triglyceride; $\mathrm{TC}=$ total cholesterol.

strain No. 14 has been shown to reduce HFD-induced increases of plasma TC without having an effect on mice fed an ND (Okubo et al., 2013). Furthermore, other strains of Lactobacillus also showed a similar beneficial effect on HFD-induced hypercholesterolemia and hypertriglyceridemia without any significant effect on the mice fed an ND (Park et al., 2014).

Next, HDL:TC, HDL-C:LDL-C, and TG:HDL-C ratios were estimated as atherogenic indices. As shown in Table 5, the HDL:TC ratio in the ND and HFD-NS1 groups were 0.84 and 0.78 , respectively, whereas the value for the HFD-only group was approximately 0.69 .
Furthermore, the ratios of HDL-C to LDL-C in the ND, HFD, and HFD-NS1 groups were 2.62, 1.82, and 2.12, respectively. In addition, the ratio of TG to HDL-C in HFD-NS1 mice was 0.31, which is $48 \%$ lower than that of HFD-fed mice, suggesting that L. acidophilus NS1 has a positive effect on plasma lipid profile.

\section{Effect of L. acidophilus NS1 on Expression of Hepatic Genes Involved in Cholesterol Metabolism}

Because the liver is the major organ for lipid metabolism, we analyzed the hepatic lipid profile to determine the effect of L. acidophilus NS1 on HFD-induced cholesterol and TG levels in the liver. As shown in Figure 3A, an HFD increased hepatic cholesterol and TG levels approximately 86 and $26 \%$, respectively, compared with an ND. However, when HFD-NS1 was administered for the whole period, hepatic cholesterol and TG levels were decreased to 34 and $82 \%$, respectively, compared with HFD-fed mice. These values are similar to those of ND-fed mice. Altogether, these data suggest that L. acidophilus NS1 may reduce HFD-induced hepatic cholesterol and TG levels.

(A)
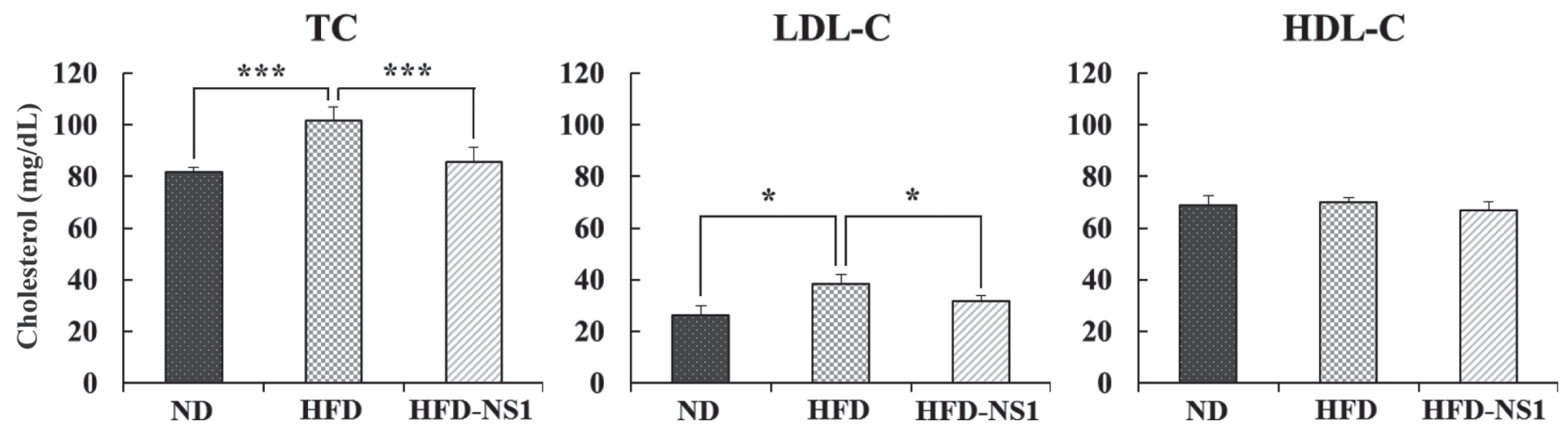

(B)

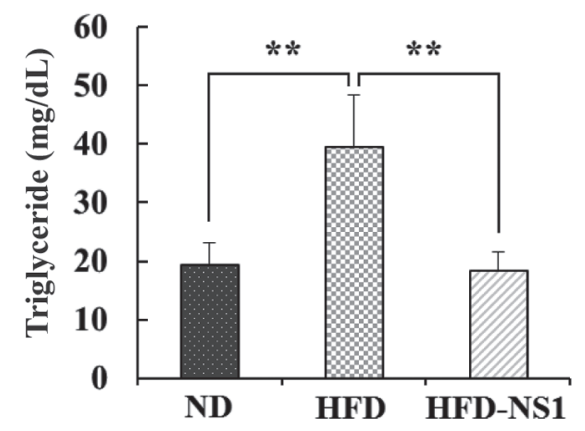

Figure 2. Lactobacillus acidophilus NS1-induced reduction of plasma lipid levels in high-fat diet (HFD)-fed mice. (A) Plasma concentration of total cholesterol (TC), low-density lipoprotein cholesterol (LDL-C), high-density lipoprotein cholesterol (HDL-C), and (B) triglycerides in mice fed a normal diet (ND), HFD, or HFD with L. acidophilus NS1 (HFD-NS1) for 10 wk. Data represent mean \pm SD for ND $(\mathrm{n}=6)$, HFD ( $=$ $5)$ and HFD-NS1 mice $(\mathrm{n}=6)$. ${ }^{*} P<0.05 ;{ }^{* *} P<0.01$; ${ }^{* * *} P<0.001$. 
(A)
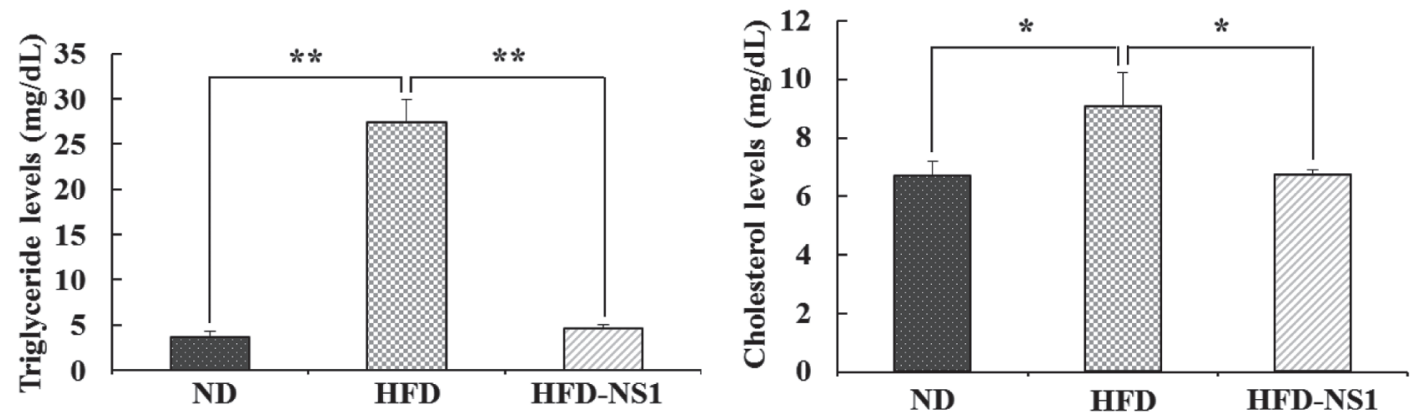

(B)
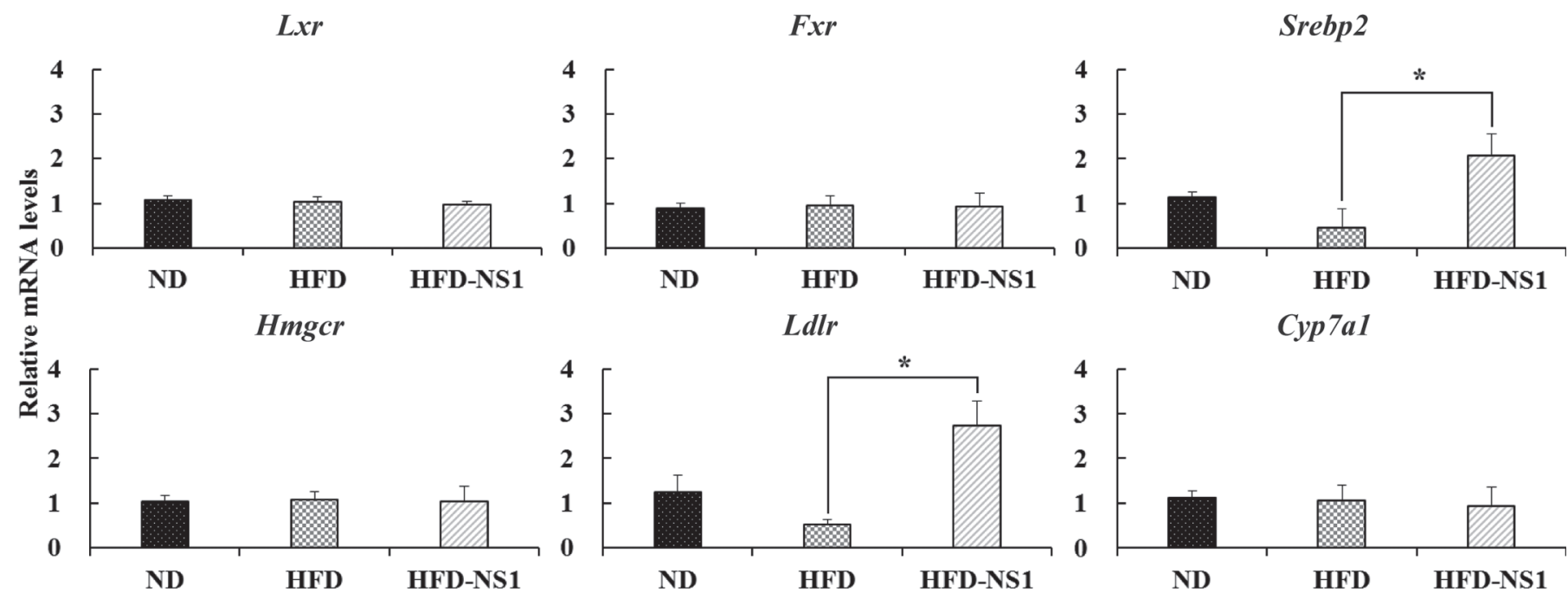

Figure 3. The effect of Lactobacillus acidophilus NS1 on lipid accumulation and expression of genes involved in cholesterol metabolism in the liver of high-fat diet (HFD)-fed mice. (A) Triglyceride and cholesterol contents in livers of mice fed a normal diet (ND), HFD, or HFD with $L$. acidophilus NS1 (HFD-NS1) for 10 wk. (B) Expression of hepatic genes was determined by real-time PCR. Data represent mean $\pm \mathrm{SD}(\mathrm{n}=3$ ). ${ }^{*} P<0.05 ;{ }^{* *} P<0.01$. Genes: $L x r=$ liver X receptor; Fxr $=$ farnesoid X receptor; Srebp2 = sterol regulatory element-binding protein $2 ;$ Hmgcr $=$ hydroxymethyl glutarate-CoA reductase; $L d l r=$ low-density lipoprotein receptor; Cyp $7 a 1=$ cholesterol $7 \alpha$-hydroxylase.

The liver is a key organ for cholesterol homeostasis, and a variety of hepatic genes are involved in cholesterol synthesis, cholesterol uptake or conversion of cholesterol to bile acids. Thus, we analyzed mRNA levels of hepatic genes involved in cholesterol metabolism. As shown in Figure 3B, expression of sterol regulatory element-binding protein 2 (Srebp2) and $L d l r$ genes in the liver was dramatically reduced in HFD-fed mice compared with ND-fed mice. However, HFD feeding did not significantly affect the mRNA levels of other hepatic genes, such as HMG-CoA reductase (Hmg-cr), cholesterol 7 -hydroxylase (Cyp 7a1), liver X receptor $(L x r)$, and farnesoid $\mathrm{X}$ receptor $(F x r)$, which are critical for cholesterol or bile acid synthesis. When $L$. acidophilus NS1 was administered orally to mice fed an HFD, HFD-induced suppression of hepatic Srebp2 and $L d l r$ expression was significantly reversed. In con- trast, expression of the Hmg-cr, Cyp 7a1, Lxr, and Fxr genes was not significantly affected by $L$. acidophilus NS1. Plasma cholesterol levels could be controlled at several steps including cholesterol synthesis, selective LDL uptake and conversion of cholesterol to bile acids in the liver (Hylemon et al., 2009). The gene $L d l r$ is responsible for LDL uptake to hepatocytes, which are essential for the clearance of circulating LDL-C. Moreover, $L d l r$-deficient mice have shown a significant increase in plasma LDL-C and are highly susceptible to atherogenesis when fed Western diets (Ballantyne, 1998). The possible mechanism by which L acidophilus NS1 abolishes HFD-induced reduction of Ldlr levels is not known. Several studies have shown that HFD feeding suppresses expression of Srebp2, which is a key transcription factor for Ldlr gene expression (Huang et al., 2008; Jia et al., 2014). Thus, it is possible that 
L. acidophilus NS1 administration leads to an increase in LDLR expression in the liver in part by recovering hepatic expression of Srebp2, which was suppressed by the HFD. Although further study will be necessary to address the molecular pathways of L. acidophilus NS1 function in cholesterol homeostasis, L. acidophilus NS1induced recovery of $L d l r$ levels in the liver may facilitate hepatic uptake of plasma LDL, thereby lowering the elevated LDL cholesterol levels induced by HFD feeding.

\section{CONCLUSIONS}

In conclusion, L. acidophilus NS1 was found to possess desirable in vitro probiotic properties by examining its acid resistance and bile acid tolerance, cholesterol assimilation activity, and adhesion to cells. This strain is a good candidate for further investigation with in vivo studies to determine its potential health benefits. Administration of L. acidophilus NS1 reduces plasma LDL-C by increasing hepatic Ldlr expression in an HFD-fed mouse model, although these outcomes in mice fed an HFD-NS1 could not be directly applied to mice fed an ND. At present, we do not know whether L. acidophilus NS1 has a beneficial effect on mice fed an ND. As ND feeding helps to maintain healthy gut microbiota, L. acidophilus NS1 may not have a dramatic effect on lipid profiles under ND feeding conditions. However, a long-term study will be required to define the systematic role of $L$. acidophilus NS1 in lipid homeostasis under ND conditions.

\section{ACKNOWLEDGMENTS}

This work was supported in part by grants from the Nong Shim Funds, Seoul, Republic of Korea. No potential conflicts of interest relevant to this article were reported.

\section{REFERENCES}

Anderson, R. N. 2002. Deaths: Leading causes for 2000. Natl. Vital Stat. Rep. 50:1-85.

Ballantyne, C. M. 1998. Current thinking in lipid lowering. Am. J. Med. 104:33S-41S

Brown, M. S., and J. L. Goldstein. 1986. A receptor-mediated pathway for cholesterol homeostasis. Science 232:34-47.

Buck, L. M., and S. E. Gilliland. 1994. Comparison of freshly isolated strains of Lactobacillus acidophilus of human intestinal origin for ability to assimilate cholesterol during growth. J. Dairy Sci. 77:2925-2933.

Daniel, H., A. Moghaddas Gholami, D. Berry, C. Desmarchelier, H. Hahne, G. Loh, S. Mondot, P. Lepage, M. Rothballer, A. Walker, C. Böhm, M. Wenning, M. Wagner, M. Blaut, P. Schmitt-Kopplin, B. Kuster, D. Haller, and T. Clavel. 2014. High-fat diet alters gut microbiota physiology in mice. ISME J. 8:295-308. du Toit, M., C. M. A. P. Franz, L. M. T. Dicks, U. Schillinger, P. Haberer, B. Warlies, F. Ahrensc, and W. H. Holzapfela. 1998. Characterisation and selection of probiotic lactobacilli for a preliminary minipig feeding trial and their effect on serum cholesterol levels, faeces $\mathrm{pH}$ and faeces moisture content. Int. J. Food Microbiol. 40:93-104.

Dunne, C., L. O’Mahony, L. Murphy, G. Thornton, D. Morrissey, S. O'Halloran, M. Feeney, S. Flynn, G. Fitzgerald, C. Daly, B. Kiely, E. M. M. Quigley, G. C. O'Sullivan, F. Shanahan, and J. K. Collins. 2001. In vitro selection criteria for probiotic bacteria of human origin: Correlation with in vivo findings. Am. J. Clin. Nutr. $73: 386 \mathrm{~S}-392 \mathrm{~S}$.

Huang, Z., X. Zhou, A. C. Nicholson, A. M. Gotto Jr., D. P. Hajjar, and J. Han. 2008. Activation of peroxisome proliferator-activated receptor- $\alpha$ in mice induces expression of the hepatic low-density lipoprotein receptor. Br. J. Pharmacol. 155:596-605.

Hylemon, P. B., H. Zhou, W. M. Pandak, S. Ren, G. Gil, and P. Dent 2009. Bile acids as regulatory molecules. J. Lipid Res. 50:15091520.

Hyronimus, B., C. Le Marrec, A. Hadj Sassi, and A. Deschamps. 2000 Acid and bile tolerance of spore-forming lactic acid bacteria. Int. J. Food Microbiol. 61:193-197.

Jia, Y. J., R. X. Xu, J. Sun, Y. Tang, and J. J. Li. 2014. Enhanced circulating PCSK9 concentration by berberine through SREBP-2 pathway in high fat diet-fed rats. J. Transl. Med. 12:103.

Kandler, O., and N. Weiss. 1986. Regular non-sporing Gram positive rods. Pages 1208-1234 in Bergey's Manual of Systematic Bacteriology, Vol. 2, Sneath, P.H.A., M. E. Sharpe, and J. G. Holt, William and Wilkins, Baltimore, MD.

Kermanshahi, R. K., and S. Peymanfar. 2012. Isolation and identification of lactobacilli from cheese, yoghurt and silage by $16 \mathrm{~S}$ rDNA gene and study of bacteriocin and biosurfactant production. Jundishapur J. Microbiol. 5:528-532.

Kim, S. J., S. Y. Cho, S. H. Kim, O. J. Song, I. S. Shin, D. S. Cha and H. J. Park. 2008. Effect of microencapsulation on viability and other characteristics in Lactobacillus acidophilus ATCC 43121. LWT- . Food Sci. Technol. (Campinas.) 41:493-500.

Lee, H. Y., J. H. Park, S. H. Seok, M. W. Baek, D. J. Kim, K. E. Lee, K. S. Paek, Y. Lee, and J. H. Park. 2006. Human originated bacteria, Lactobacillus rhamnosus PL60, produce conjugated linoleic acid and show anti-obesity effects in diet-induced obese mice. Biochim. Biophys. Acta 1761:736-744.

Lim, S. M. 2014. Antimutagenicity activity of the putative probiotic strain Lactobacillus paracasei ssp. tolerans JG22 isolated from pepper leaves Jangajji. Food Sci. Biotechnol. 23:141-150.

Liong, M. T., and N. P. Shah. 2005. Acid and bile tolerance and cholesterol removal ability of lactobacilli strains. J. Dairy Sci. 88:55-66.

Manson, J. E., H. Tosteson, P. M. Ridker, S. Satterfield, P. Hebert, G. T. O'Connor, J. E. Buring, and C. H. Hennekens. 1992. The primary prevention of myocardial infarction. N. Engl. J. Med. 326:1406-1416.

Merrell, D. S., and A. Camilli. 2002. Acid tolerance of gastrointestinal pathogens. Curr. Opin. Microbiol. 5:51-55.

Nguyen, T. D. T., J. H. Kang, and M. S. Lee. 2007. Characterization of Lactobacillus plantarum $\mathrm{PH} 04$, a potential probiotic bacterium with cholesterol-lowering effects. Int. J. Food Microbiol. 113:358-361.

Okubo, T., N. Takemura, A. Yoshida, and K. Sonoyama. 2013. KK/ Ta mice administered Lactobacillus plantarum strain No. 14 have lower adiposity and higher insulin sensitivity. Biosci. Microbiota Food Health 32:93-100.

Ooi, L. G.. and M. T. Liong. 2010. Cholesterol-lowering effects of probiotics and prebiotics: A review of in vivo and in vitro findings. Int. J. Mol. Sci. 11:2499-2522.

Park, J. E., S. H. Oh, and Y. S. Cha. 2014. Lactobacillus plantarum LG42 isolated from gajami sik-hae decreases body and fat pad weights in diet-induced obese mice. J. Appl. Microbiol. 116:145156. 
Park, S. S., H. Choi, S. J. Kim, O. J. Kim, K. S. Chae, and E. S. Kim. 2008a. FXR alpha down-regulates LXR alpha signaling at the CETP promoter via a common element. Mol. Cells 26:409-414.

Park, Y. H., J. G. Kim, Y. W. Shin, H. S. Kim, Y. J. Kim, T. Chun, S. H. Kim, and K. Y. Whang. 2008b. Effects of Lactobacillus acidophilus 43121 and a mixture of Lactobacillus casei and Bifidobacterium longum on the serum cholesterol level and fecal sterol excretion in hypercholesterolemia-induced pigs. Biosci. Biotechnol. Biochem. 72:595-600.

Pereira, D. I. A., and G. R. Gibson. 2002. Cholesterol assimilation by lactic acid bacteria and bifidobacteria isolated from the human gut. Appl. Environ. Microbiol. 68:4689-4693.

Spady, D. K. 1992. Hepatic clearance of plasma low density lipoproteins. Semin. Liver Dis. 12:373-385.

Tanida, M., J. Shen, K. Maeda, Y. Horii, T. Yamano, Y. Fukushima, and K. Nagai. 2008. High-fat diet-induced obesity is attenuated by probiotic strain Lactobacillus paracasei ST11 (NCC2461) in rats. Obes. Res. Clin. Pract. 2:I-II.

Wang, J., H. Zhang, X. Chen, Y. Chen, Menghebilige, and Q. Bao. 2012. Selection of potential probiotic lactobacilli for cholesterollowering properties and their effect on cholesterol metabolism in rats fed a high-lipid diet. J. Dairy Sci. 95:1645-1654.

Xie, N., Y. Cui, Y. N. Yin, X. Zhao, J. W. Yang, Z. G. Wang, N. Fu, Y. Tang, X. H. Wang, X. W. Liu, C. L. Wang, and F. G. Lu. 2011 Effects of two Lactobacillus strains on lipid metabolism and intestinal microflora in rats fed a high-cholesterol diet. BMC Complement. Altern. Med. 11:53-63.

Yoo, S. R., Y. J. Kim, D. Y. Park, U. J. Jung, S. M. Jeon, Y. T. Ahn, C. S. Huh, R. McGregor, and M. S. Choi. 2013. Probiotics L. plantarum and L. curvatus in combination alter hepatic lipid metabolism and suppress diet-induced obesity. Obesity (Silver Spring) 21:2571-2578. 